\title{
Motivação à luz da teoria da autodeterminação: uma análise comparativa do processo motivacional de concluintes dos mestrados acadêmico e profissional em administração
}

\author{
Motivation in the light of the \\ self-determination theory: a comparative \\ analysis of the motivational process of seniors \\ of the academic and professional \\ master's in business administration
}

\author{
MILER FRANCO D'ANJOUR* \\ BRUNO CAMPELO MEDEIROS** \\ MÁRCIA FERNANDA SILVA MACEDO GALVÃO*** \\ ANNE EMÍLIA COSTA CARVALHO****
}

\section{RESUMO}

O presente artigo tem como objetivo geral compreender de forma comparativa o processo motivacional dos alunos para conclusão dos cursos de mestrado acadêmico e profissional em Administração à luz da teoria da autodeterminação. Para tanto, foi adotado um enfoque analítico qualitativo, tendo como plano básico de pesquisa o estudo comparativo e o interacionismo simbólico como postura teórica. A coleta de dados foi realizada por meio de entrevista focalizada com uso da foto-elicitação. O método de

* Instituto Federal de Educação Ciência e Tecnologia do Rio Grande do Norte. miler.danjour@ifrn.edu.br

** Instituto Federal de Educação Ciência e Tecnologia do Rio Grande do Norte. bruno.campelo@ifrn.edu.br

*** Universidade Federal do Rio Grande do Norte/UFRN. marciafernandasm@yahoo.com.br

**** Universidade Federal do Rio Grande do Norte/UFRN. anneeccarvalho@gmail.com 
interpretação foi a análise de conteúdo, realizada com auxílio do software NVivo, que possibilitou a análise comparativa e análises intra-casos e inter-casos, por meio de análise de agrupamento, modelos hierárquicos e tabelas de frequência. Os resultados demostraram que os mestrados profissional e acadêmico exibem a mesma sequência motivacional, com prevalência da motivação extrínseca, depois da motivação intrínseca e por fim da desmotivação. Entretanto, existem diferenças entre os níveis de motivação extrínseca. Os mestres oriundos dos mestrados acadêmico e profissional apresentaram um processo motivacional com alto grau de autonomia, no entanto, ainda considerando estímulos internos ou externos.

Palavras-chave: Motivação; Teoria da Autodeterminação; Mestrado Acadêmico; Mestrado Profissional; Análise de Conteúdo.

\section{ABstract}

The present study tries to understand comparative form the students ' motivational process for completion of academic and professional Masters courses in business administration in the light of self-determination theory. Thus, it was adopted a qualitative analytical approach, taking as basic plan of research the comparative study and the symbolic interactionism as theoretical position. The data were collected by means of focused interview with use of photo-elicitation. The method of interpretation was the content analysis, performed with the aid of the NVivo software, which enabled the comparative intra-case and inter-case analysis, through cluster analysis, hierarchical models and frequency tables. The results demonstrated that the professional and academic master's exhibit the same motivational sequence, with prevalence of extrinsic motivation, intrinsic motivation and finally the demotivation. However, there are differences between the levels of extrinsic motivation. The masters from the academic and professional masters presented a motivational process with a high degree of autonomy, however, still considering internal or external stimuli.

Key words: Motivation; Self-determination Theory; Academic Master's; Professional Master's; Content analysis. 


\section{INTRODUÇÃo}

A compreensão da motivação humana tem sido perseguida por pesquisadores em diversas áreas do conhecimento. Trata-se de um tema relevante e complexo, uma vez que a motivação é um construto hipotético, elaborado com o intuito de explicar, compreender e prever os comportamentos, e refere-se às necessidades e metas pessoais internamente organizadas na estrutura da personalidade" (MAYER; FABER; XU, 2007; BORUCHOVITCH, 2008; MACHADO et al, 2012).

Um dos campos que tem explorado o tema da motivação é o da educação, em seus diversos níveis, sendo a Teoria da Autodeterminação (Self-Determination Theory - SDT) bastante utilizada para compreender as relações existentes entre aprendizagem e desempenho com a motivação humana (SCHUNK,1991; MITCHELL JR, 1992; WECHSLER, 2006; LEAL; MIRANDA; DE NAEGHEL, 2012; JANG; KIM; REEVE, 2012; CARMO, 2013; MADJAR, COHEN-MALAYEV, 2013; SHEN, 2014; KELLY; SHOGREN, 2014). De acordo com Lens, Matos e Vansteenkiste (2008), independentemente do nível educacional, é importante que os alunos estejam motivados para realização de suas atividades acadêmicas, pois seu estado motivacional interfere na quantidade de tempo dedicado, nas realizações acadêmicas, nos resultados alcançados e no seu bem-estar ou mal-estar. Nesse sentido, estudos na área da educação podem se utilizar das diversas teorias motivacionais para promover suas análises, com destaque para a teoria da autodeterminação, que tem se mostrado relevante para discutir o comportamento intrinsicamente motivado no ambiente educacional.

Entre as realizações perseguidas ao longo da vida acadêmica, destaca-se no presente estudo, a pós-graduação stricto sensu (mestrado e doutorado). Dados do "Plano Nacional de Pós-graduação (PNPG) 2011-2020" (CAPES, 2010) apontam para o crescimento da pós-graduação brasileira em número de cursos e, consequentemente, de discentes, e reforçam a relevância da pós-graduação para o desenvolvimento do país. Nesse contexto, a grande área de conhecimento das Ciências Sociais Aplicadas é uma das áreas com maior crescimento de cursos de mestrado e doutorado. Ao final do ano de 2009, a área estava entre as que concentravam o maior número de discentes de mestrado acadêmico e mestrado profissional. 
De acordo com os documentos referentes à Avaliação Trienal da Capes (2013), na grande área de conhecimento das Ciências Sociais Aplicadas destaca-se a área de avaliação de Administração, Ciências Contábeis e Turismo por apresentar o maior número de programas de pós-graduação, sendo a subárea de Administração aquela que reúne a maioria dos programas. Destaca-se ainda o aumento de programas de mestrado profissional, saindo de 26 em 2009 para 50 no final de 2012 (CAPES 2013). A expansão do número de cursos de mestrado e doutorado é visto como um avanço do Sistema Nacional de Pós-graduação. No entanto, esse crescimento deve ser objeto de análises constantes para que os objetivos do sistema sejam alcançados. Nesse sentido, Velho (2005) destaca que questões relacionadas com a qualidade da formação de mestres e doutores, sua inserção no mercado de trabalho, dados de evasão e as razões que motivam o abandono dos cursos precisam ser mais exploradas.

Partindo do último ponto abordado por Velho (2005), a questão do abandono dos cursos de pós-graduação, apesar de não terem sido localizados relatórios ou estudos recentes que discutam dados consolidados de desligamento e abandono de discentes de pós-graduação no Brasil, é possível verificar, nos diversos programas de pós-graduação avaliados pela Coordenação de Aperfeiçoamento de Pessoal de Nível Superior (Capes) casos de saída por abandono ou desligamento em seus fluxos discentes. Tomando como exemplo o caso da pós-graduação em Administração da UFRN, das 50 saídas registradas no fluxo discente do curso de mestrado entre 2010 e 2013, 18 ocorreram por desligamento ou abandono, totalizando $36 \%$ das saídas, com uma média de 4,5 casos por ano (CAPES 2013).

Neste contexto, o presente estudo apresenta como quentão central de pesquisa identificar: como se caracteriza o processo motivacional dos alunos para conclusão dos cursos de mestrado acadêmico e profissional em Administração? Sendo o objetivo geral do estudo compreender de forma comparativa o processo motivacional dos alunos para conclusão dos cursos de mestrado acadêmico e profissional em Administração à luz da teoria da autodeterminação.

A relevância da pesquisa se sustenta tanto do ponto de vista acadêmico quanto do ponto de vista social. A expansão do número de cursos de mestrado e doutorado no Brasil é visto como um 
avanço do Sistema Nacional de Pós-graduação. No entanto, esse crescimento deve ser objeto de análises constantes para que os objetivos do sistema sejam alcançados. Nesse sentido, Velho (2005) destaca que questões relacionadas com a qualidade da formação de mestres e doutores, sua inserção no mercado de trabalho, dados de evasão e as razões que motivam o abandono dos cursos precisam ser mais exploradas.

Partindo do último ponto abordado por Velho (2005), a questão do abandono dos cursos de pós-graduação, apesar de não terem sido localizados relatórios ou estudos recentes que discutam dados consolidados de desligamento e abandono de discentes de pósgraduação no Brasil, é possível verificar nos diversos programas de pós-graduação avaliados pela Coordenação de Aperfeiçoamento de Pessoal de Nível Superior (Capes) casos de saída por abandono ou desligamento em seus fluxos discentes. Tomando como exemplo o caso da pós-graduação em Administração da UFRN, que foi discutido neste estudo, das 50 saídas registradas no fluxo discente do curso de mestrado entre 2010 e 2013, 18 ocorreram por desligamento ou abandono, totalizando $36 \%$ das saídas, com uma média de 4,5 casos por ano.

No que se refere à relevância acadêmica do estudo, trata-se de uma temática que ainda não foi devidamente explorada no âmbito nacional. Não foram identificados estudos recentes abordando o processo motivacional na pós-graduação sob a ótica da teoria da autodeterminação. No contexto do ensino, alguns estudos utilizaram como teoria-base a teoria da autodeterminação, focando a motivação de alunos para o contexto do curso em si (LEAL; MIRANDA; CARMO, 2013; GUIMARÃES; BZUNECK, 2008; OLIVEIRA et al, 2010), ou o estilo motivacional do professor como fonte para a motivação dos alunos (LENS; MATOS; VANSTEENKISTE, 2008; GUIMARÃES; BORUCHOVITCH, 2004; BZUNECK; GUIMARAES, 2007), porém não levaram em consideração o contexto da pós-graduação. Este estudo também contribui para preencher a lacuna metodológica nas aplicações da teoria da autodeterminação na área da educação, no que se refere ao enfoque analítico qualitativo, com uso de entrevista focalizada e foto-elicitação como método de coleta de dados e análise de conteúdo como estratégia para interpretação dos dados. 
Assim sendo, este artigo foi dividido em seis seções: esta introdução, o embasamento teórico sobre motivação, conceitos básicos e aplicações da teoria da autodeterminação, procedimento metodológicos para a operacionalização da pesquisa, análise de resultados e, por fim, as considerações finais do estudo.

\section{TEORIA DA AUTODETERMINAÇÃo: ORIGEM E CONCEITOS}

Os estudos acerca da motivação humana no início da década de 1950 passam de uma abordagem mais filosófica para uma abordagem que busca compreender e explicar o comportamento dos indivíduos a partir da união de elementos da psicologia com elementos gerenciais. Desta forma, busca-se compreender a motivação humana não apenas pelo sujeito de maneira isolada, mas pelos elementos contingenciais que estes interagem em sua dinâmica em sociedade (SZILAGYI; WALLACE, 1990; JANG; KIM; REEVE, 2012).

As principais teorias que estudaram a motivação humana, segundo Lobos (1975), buscaram explicar tanto os elementos relacionados aos indivíduos e às situações que definem a conduta, quanto aos elementos que buscam construir uma explicação para o processo ao qual a ação "se inicia", "se mantém" e "termina". Dentro do primeiro grupo observam-se as teorias motivacionais ditas de conteúdo e no segundo grupo as teorias motivacionais ditas de processos (SZILAGYI; WALLACE, 1990; WELTERS; MITCHELL; MUYSKEN, 2014).

Dentre estas teorias motivacionais, destacam-se as abordagens ditas de processo, em especial a teoria da expectativa de Vroom que gerou bases para o desenvolvimento da teoria da autodeterminação, discutida no presente artigo. Advinda das bases do construto da teoria da expectativa de Vroom (GAGNÉ; DECI, 2005; MORAN, 2012; LEAL; MIRANDA; CARMO, 2013), a teoria da autodeterminação ((Self-Determination Theory-SDT), proposta por Deci e Ryan (1985) busca estudar por meio do estabelecimento de um contínuo as características dos níveis de motivação menos autônomos aos níveis de maior autonomia motivacional dos indivíduos.

De acordo com Deci e Ryan (1985), a autodeterminação é uma qualidade humana que envolve uma experiência de escolha de acordo com a percepção interna do indivíduo relacionada a um 
comportamento intrinsecamente motivado ou um comportamento extrinsecamente motivado. Segundo a teoria, o indivíduo está intrinsecamente motivado em realizar uma determinada atividade pela espontânea satisfação em realizá-la (FERGUSON et al, 2015). Desta forma, Deci e Ryan (1985) fazem um contraponto ao estudo de Skineer, ao afirmarem que ocomportamento intrinsecamente motivado seria independente de consequências, porque a realização da atividade seria a própria recompensa (GUIMARÃES; BORUCHOVITCH, 2004, FERGUSON et al, 2015). Já a motivação extrínseca está associada a uma possível consequência que o indivíduo possa sofrer decorrência da realização ou não daquela atividade, e por isso, se motiva a fazê-la (KELLY; SHOGREN, 2014; WELTERS; MITCHELL; MUYSKEN, 2014).

Lens, Matos e Vanteenkiste (2008) complementam este conceito, ao considerar que a motivação intrínseca satisfaz a três necessidades humanas psicológicas básicas: as necessidades de autonomia, de competência e de relação, ou seja, ao bem-estar psicológico. Estas necessidades não são aprendidas, e sim inerentes ao aspecto da natureza humana (DECI; VANSTEENKISTE, 2004). Por sua vez, quando o indivíduo está mais predisposto à motivação extrínseca, ele tende a ser orientado a comparações interpessoais, traduzindo, assim, em baixo bem-estar e menor persistência (MORAN, 2012).

No entanto, realizar uma análise apenas observando a dicotomia entre a motivação intrínseca e a motivação extrínseca limita a compreensão da situação, pois, mesmo que as pessoas executem atividades reguladas por motivações extrínsecas, poderá haver também envolvimento e resultados semelhantes às características típicas da motivação intrínseca (GUIMARÃES; BZUNECK, 2008). Para isso, a teoria da autodeterminação estabelece cinco tipos de regulação comportamental, uma associada à motivação intrínseca e quatro associadas à motivação extrínseca, gerando o continuum de motivação descrito na Figura 1. 
Figura 1 - Continuum da autodeterminação.

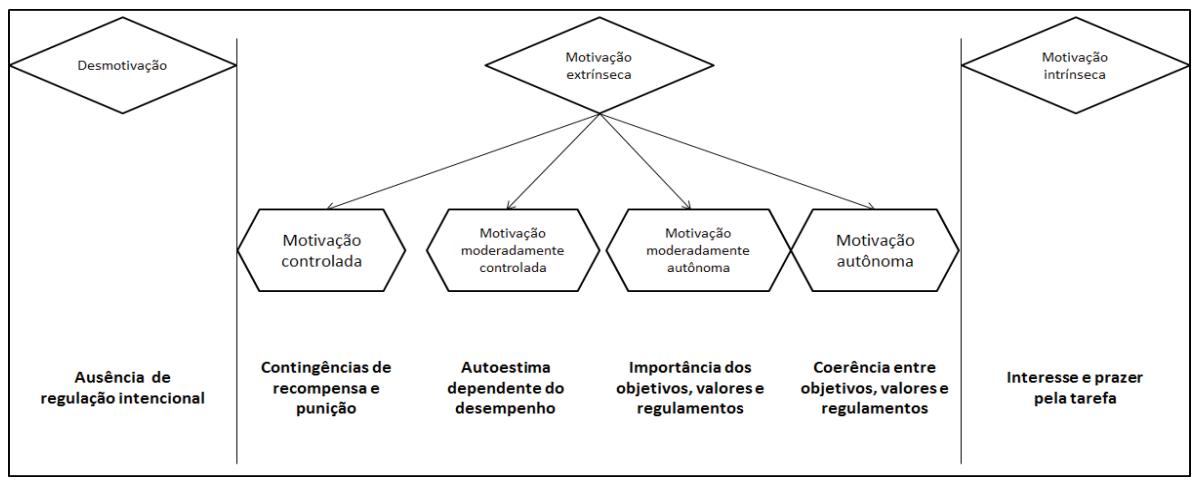

Fonte: Adaptado de Gagné e Deci (2005).

De acordo com Gagné e Deci (2005), o comportamento intrinsecamente motivado é movido por interesse das pessoas na própria atividade realizada, ou seja, pelo interesse pessoal. Este tipo de motivação é conhecido como motivação autônoma inerente, e envolve aspectos bastante pessoais, como a liberdade psicológica e a percepção de escolha do indivíduo (GUIMARÃES; BZUNECK, 2008; DE NAEGHEL, 2012; FERGUSON et al, 2015).

Contudo, existem atividades que são realizadas, sobretudo, devido a fatores externos que regulam, de certa forma, o comportamento do indivíduo. Tais fatores englobam uma categoria conhecida como motivação extrínseca, que, por sua vez, é subdividida em quatro categorias de motivação, de acordo com o seu nível de regulação. A motivação controlada é o tipo mais básico de motivação extrínseca, na qual a pessoa age para obter recompensas ou evitar punições (LEAL; MIRANDA; CARMO, 2013; WELTERS; MITCHELL; MUYSKEN, 2014). Este tipo de motivação envolve uma regulação externa para que haja um comportamento proativo em relação à realização de uma atividade. Já a motivação moderadamente controlada está associada às consequências contingentes que são administradas pela própria pessoa, sendo resultado de pressões internas como culpa, ansiedade ou busca de reconhecimento pessoal (GUIMARÃES; BZUNECK, 2008). Por isso, se tem aqui uma regulação introjetada, interna ao indivíduo. Estas duas primeiras categorias de motivação extrínseca não são autodeterminadas ou autônomas, e sim tipos de 
motivação controlada, uma de forma puramente externa, e outra internamente (RUFINI, BZUNECK; OLIVEIRA, 2011; MORAN, 2012).

Na motivação moderadamente autônoma, relacionada à regulação identificada, existe um equilíbrio em termos de razão pela qual o indivíduo realiza uma determinada atividade, tendo origem tanto externa quanto interna. Em termos de motivação para o estudo, por exemplo, a motivação do aluno para estudar é algo instrumental, relacionada a algo externo, mas este mesmo aluno se identifica com a razão para estudar (LENS; MATOS; VANSTEENKISTE, 2008; MORAN, 2012).

O último nível de motivação extrínseca está associado à regulação integrada, onde se caracteriza pelo comportamento assumido por escolha pessoal, com autonomia completa e sem coação, e por isso, ela é conhecida como motivação autônoma. No entanto, embora este nível de motivação se caracterize por um alto grau de autonomia, há um componente externo que dá sentido à ação, o que difere da motivação intrínseca (RUFINI; BZUNECK; OLIVEIRA, 2011; FERGUSON et al, 2015).

Ainda existe, segundo o modelo apresentado por Gagné e Deci (2005), a situação de desmotivação do indivíduo, ou seja, o indivíduo não apresenta a intenção nem o comportamento proativo (LEAL; MIRANDA; CARMO, 2013). Neste caso, não há influência externa nem interna que provoque um comportamento proativo para a realização de uma determinada atividade.

Diante do que foi exposto, percebe-se que existem diferentes tipos de motivação, e que cada tipo de motivação pode apresentar uma maior ou menor autodeterminação do indivíduo (MORAN, 2012). As pesquisas relacionadas à teoria da autodeterminação afirmam que os tipos de motivação autodeterminada são encontrados na motivação intrínseca e nas motivações extrínsecas por regulação integrada e por regulação identificada (RIBEIRO, 2013). Com isso, entende-se que estes níveis de motivação apresentam maior autonomia do indivíduo no tocante ao seu comportamento para a realização de uma determinada atividade. Já os níveis de motivação extrínseca relacionados à regulação externa e à regulação introjetada são associados a um maior controle de fatores externos sobre o indivíduo, e, portanto, não há a presença da autodeterminação. 
Para efeitos da presente pesquisa, é importante salientar que, em se tratando da teoria da autodeterminação, alguns estudos foram desenvolvidos levando em consideração a problemática da aprendizagem e da motivação para o estudo, na tentativa de entender as diferentes fontes de motivação intrínseca e extrínseca (SCHUNK,1991; MITCHELL JR, 1992; WECHSLER, 2006; LEAL; MIRANDA; DE NAEGHEL, 2012; JANG; KIM; REEVE, 2012; CARMO, 2013; MADJAR, COHEN-MALAYEV, 2013; SHEN, 2014; KELLY; SHOGREN, 2014). Uma conclusão importante, afirmada por Siqueira e Weschler (2006), revela que ainda existem muitas dúvidas que expliquem tais diferenças, principalmente sobre a influência de esforços e recompensas sobre a motivação intrínseca. Uma possível conclusão, segundo os autores, é que estas diferenças não sejam explicadas pelo nível de recompensa, e sim, como este processo de oferecer algo é realizado, e principalmente, como pode ser entendido por quem o recebe (MORAN, 2012).

Outra questão importante, afirmada por Bzuneck e Guimarães (2007), é que as formas de motivação autodeterminadas, tais como a motivação intrínseca, dependem, de maneira positiva, de comportamentos interpessoais, promotores da autonomia. Assim, tendo como base a motivação para o estudo, quando se tem um comportamento proativo, relacionado ao processo de autonomia do aluno, a motivação intrínseca se torna presente, e mais fácil será o processo de resposta do aluno a outros estímulos (FERGUSON et al, 2015).

\section{PRINCIPAIS CAMPOS DE ESTUdo E APLICAÇões RECENTES}

Por meio da sistematização da produção científica divulgada no Portal SDT - Self-Determination Theory, foi possível identificar os principais campos de estudo da teoria da autodeterminação, conforme demonstrado na Tabela 1 . 
Tabela 1 - Principais campos de estudo com a teoria da autodeterminação.

\begin{tabular}{|c|c|c|c|c|c|c|c|}
\hline \multirow[b]{2}{*}{ Campo } & \multicolumn{7}{|c|}{ Quantidade de Aplicações } \\
\hline & $\begin{array}{l}\text { Década } \\
\text { de } 1980\end{array}$ & \begin{tabular}{|l|}
$1990-$ \\
1994 \\
\end{tabular} & $\begin{array}{l}1995- \\
1999 \\
\end{array}$ & \begin{tabular}{|l|}
$2000-$ \\
2004
\end{tabular} & \begin{tabular}{|l|}
$2005-$ \\
2009 \\
\end{tabular} & $\begin{array}{l}2010- \\
2014\end{array}$ & Total \\
\hline $\begin{array}{l}\text { Esporte, Exercí- } \\
\text { cio e Educação } \\
\text { Física }\end{array}$ & 4 & 5 & 18 & 43 & 118 & 76 & 264 \\
\hline Educação & 10 & 16 & 10 & 30 & 52 & 36 & 154 \\
\hline Saúde & & 1 & 10 & 12 & 35 & 46 & 104 \\
\hline $\begin{array}{l}\text { Organizações e } \\
\text { Trabalho }\end{array}$ & 1 & 4 & 3 & 10 & 25 & 31 & 74 \\
\hline Psicopatologia & 3 & 1 & & 3 & 10 & 7 & 24 \\
\hline $\begin{array}{l}\text { Ambientes } \\
\text { Virtuais e Vídeo } \\
\text { Games }\end{array}$ & & & & & 7 & 13 & 20 \\
\hline $\begin{array}{l}\text { Psicoterapia e } \\
\text { Aconselhamento }\end{array}$ & & & 2 & 1 & 7 & 5 & 15 \\
\hline $\begin{array}{l}\text { Ambiente (Sus- } \\
\text { tentabilidade) }\end{array}$ & & & 5 & 2 & 2 & 3 & 12 \\
\hline Religião & & 3 & 1 & 1 & 4 & 3 & 12 \\
\hline Pessoas idosas & 2 & 3 & 2 & & & & 7 \\
\hline Política & & & 2 & 1 & & & 3 \\
\hline $\begin{array}{l}\text { Estudos biológi- } \\
\text { cos e neuropsi- } \\
\text { cológicos }\end{array}$ & & & & & & 2 & 2 \\
\hline $\begin{array}{l}\text { Competência } \\
\text { informacional }\end{array}$ & & & & & 2 & & 2 \\
\hline Migração & & & & & 1 & & 1 \\
\hline
\end{tabular}

Fonte: Dados da pesquisa, 2016.

O maior número de estudos publicados está relacionado ao campo de "Esporte, Exercício e Educação Física", com 264 estudos, seguido pelas áreas da "Educação", com 154 estudos, e da "Saúde", com 104 estudos. Em especial no que tange aos estudos do campo da "Educação", percebe-se que a maior concentração de trabalhos se deu entre 2005 e 2009 (52 estudos), no entanto, o período mais recen- 
te, entre 2010 e 2014, também conta com uma produção expressiva (36 estudos), demonstrando o ajuste da teoria da autodeterminação para estudos nesse campo.

Após a verificação de que o campo da "Educação" é um dos principais campos de estudo da teoria da autodeterminação, definiu-se um protocolo de revisão sistemática destinado a fazer um levantamento das aplicações recentes da teoria da autodeterminação, na esfera nacional, com o objetivo de identificar estudos no campo da "Educação" e possíveis lacunas nas aplicações desse campo nos últimos 5 anos. A fase inicial da pesquisa no Portal de Periódicos Capes resultou em 19 estudos, dos quais 12 foram selecionados, após aplicação dos filtros definidos no protocolo. Os campos identificados na pesquisa estão descritos na Figura 3.

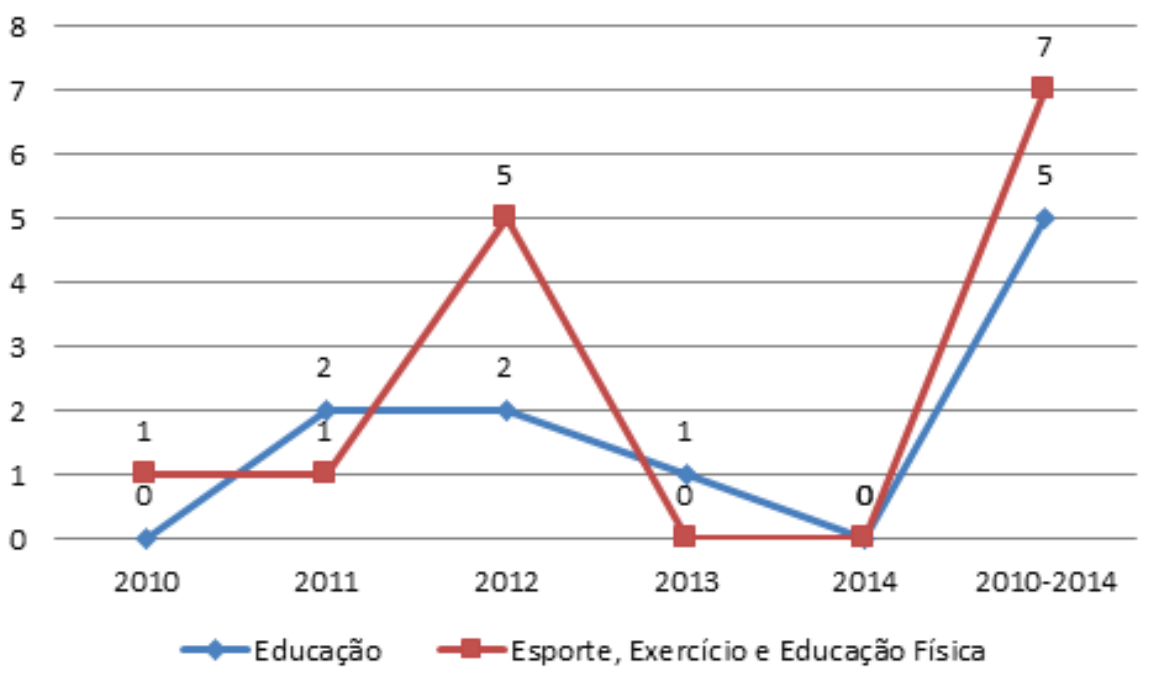

Figura 2 - Estudos nacionais com aplicação da teoria da autodeterminação. Fonte: Dados da pesquisa, 2016.

Na análise da Figura 2, verifica-se que as pesquisas nacionais, nos últimos 5 anos, têm se concentrado nos dois principais campos de aplicação da teoria da autodeterminação: “Esporte, Exercício e Educação Física" e "Educação". Os 5 estudos localizados para o campo da "Educação" estão dispostos no Quadro 1. 
Quadro 1 - Estudos nacionais com aplicação da teoria da autodeterminação.

\begin{tabular}{|c|c|c|c|c|c|}
\hline Autores & $\begin{array}{l}\text { Periódico } \\
\text { (Ano) }\end{array}$ & Título & Objetivo & $\begin{array}{l}\text { Amostra/ } \\
\text { Abrangência }\end{array}$ & $\begin{array}{l}\text { Enfoque } \\
\text { analítico }\end{array}$ \\
\hline $\begin{array}{l}\text { Maria Cristi- } \\
\text { na Rodrigues } \\
\text { Azevedo Joly; } \\
\text { Eli Andrade } \\
\text { Rocha Prates. }\end{array}$ & $\begin{array}{l}\text { Psico-USF } \\
(2011)\end{array}$ & $\begin{array}{l}\text { Avaliação } \\
\text { da Escala de } \\
\text { Motivação } \\
\text { Acadêmica } \\
\text { em estudan- } \\
\text { tes paulistas: } \\
\text { propriedades } \\
\text { psicométri- } \\
\text { cas. }\end{array}$ & $\begin{array}{l}\text { Investigar as pro- } \\
\text { priedades psicomé- } \\
\text { tricas de uma versão } \\
\text { brasileira da Escala } \\
\text { de Motivação Acadê- } \\
\text { mica (EMA). }\end{array}$ & $\begin{array}{l}170 \text { universitá- } \\
\text { rios paulistas } \\
\text { dos cursos de } \\
\text { ciências bioló- } \\
\text { gicas, educação } \\
\text { física, nutrição, } \\
\text { pedagogia e } \\
\text { psicologia. }\end{array}$ & $\begin{array}{l}\text { Quanti- } \\
\text { tativo }\end{array}$ \\
\hline $\begin{array}{l}\text { Sueli Edi Rufi- } \\
\text { ni; José Aloy- } \\
\text { seo Bzuneck; } \\
\text { Katya Luciane } \\
\text { de Oliveira. }\end{array}$ & $\begin{array}{l}\text { Psico-USF } \\
(2011)\end{array}$ & $\begin{array}{l}\text { Estudo de } \\
\text { validação de } \\
\text { uma medida } \\
\text { de avaliação } \\
\text { da moti- } \\
\text { vação para } \\
\text { alunos do } \\
\text { ensino fun- } \\
\text { damental. }\end{array}$ & $\begin{array}{l}\text { Elaborar e validar } \\
\text { um instrumento de } \\
\text { avaliação da quali- } \\
\text { dade motivacional } \\
\text { de estudantes do } \\
\text { ensino fundamental, } \\
\text { tendo por referência } \\
\text { a Teoria da Autode- } \\
\text { terminação. }\end{array}$ & $\begin{array}{l}1381 \text { estudan- } \\
\text { tes do ensino } \\
\text { fundamental } \\
\text { do estado do } \\
\text { Paraná. }\end{array}$ & $\begin{array}{l}\text { Quanti- } \\
\text { tativo }\end{array}$ \\
\hline $\begin{array}{l}\text { Amélia Caroli- } \\
\text { na Terra Alves } \\
\text { Machado; Sue- } \\
\text { li Edi Rufini; } \\
\text { Aline Guilher- } \\
\text { me Maciel; } \\
\text { José Aloyseo } \\
\text { Bzuneck. }\end{array}$ & $\begin{array}{l}\text { Psicologia: } \\
\text { Ciência e } \\
\text { Profissão } \\
(2012)\end{array}$ & $\begin{array}{l}\text { Estilos moti- } \\
\text { vacionais de } \\
\text { professores: } \\
\text { preferência } \\
\text { por controle } \\
\text { ou por auto- } \\
\text { nomia. }\end{array}$ & $\begin{array}{l}\text { Analisar as inte- } \\
\text { rações entre dois } \\
\text { professores com } \\
\text { diferentes estilos } \\
\text { motivacionais e seus } \\
\text { alunos. }\end{array}$ & $\begin{array}{l}\text { Dois professo- } \\
\text { res atuantes na } \\
\text { rede pública do } \\
\text { ensino fun- } \\
\text { damental do } \\
\text { Paraná, um com } \\
\text { estilo motiva- } \\
\text { cional promotor } \\
\text { de autonomia e } \\
\text { outro com uma } \\
\text { orientação para } \\
\text { o controle. }\end{array}$ & $\begin{array}{l}\text { Qualita- } \\
\text { tivo }\end{array}$ \\
\hline $\begin{array}{l}\text { Flávio Régio } \\
\text { Brambilla; } \\
\text { Cláudio Dama- } \\
\text { cena. }\end{array}$ & $\begin{array}{l}\text { REMark } \\
\text { : Revista } \\
\text { Brasileira } \\
\text { de Marke- } \\
\text { ting } \\
(2012)\end{array}$ & $\begin{array}{l}\text { Estudo } \\
\text { etnometo- } \\
\text { dológico da } \\
\text { cocriação de } \\
\text { valor no en- } \\
\text { sino superior } \\
\text { privado de } \\
\text { administra- } \\
\text { ção com base } \\
\text { na lógica do- } \\
\text { minante do } \\
\text { serviço em } \\
\text { marketing. }\end{array}$ & $\begin{array}{l}\text { Identificar o ponto } \\
\text { do ensino privado } \\
\text { no qual o estudante } \\
\text { como consumidor é } \\
\text { direcionado a uma } \\
\text { realidade mais pró- } \\
\text { xima da ideal para } \\
\text { aprendizagem, onde } \\
\text { o estudante é um } \\
\text { cocriador no lócus } \\
\text { educacional. }\end{array}$ & $\begin{array}{l}54 \text { (primeira } \\
\text { etapa) e } 49 \\
\text { (segunda etapa) } \\
\text { alunos do Curso } \\
\text { de Administra- } \\
\text { ção de Univer- } \\
\text { sidade privada } \\
\text { do RS. }\end{array}$ & $\begin{array}{l}\text { Qualita- } \\
\text { tivo }\end{array}$ \\
\hline $\begin{array}{l}\text { Edvalda } \\
\text { Araujo Leal; } \\
\text { Gilberto Jose } \\
\text { Miranda; } \\
\text { Carlos Roberto } \\
\text { Souza Carmo. }\end{array}$ & $\begin{array}{l}\text { Revista } \\
\text { Contabi- } \\
\text { lidade \& } \\
\text { Finanças } \\
(2013)\end{array}$ & $\begin{array}{l}\text { Teoria da } \\
\text { autodetermi- } \\
\text { nação: uma } \\
\text { analise da } \\
\text { motivação } \\
\text { dos estudan- } \\
\text { tes do curso } \\
\text { de Ciências } \\
\text { Contábeis. }\end{array}$ & $\begin{array}{l}\text { Avaliar a motivação } \\
\text { dos estudantes de } \\
\text { Ciências Contábeis } \\
\text { de uma universidade } \\
\text { pública, à luz da } \\
\text { Teoria da Autodeter- } \\
\text { minação. }\end{array}$ & $\begin{array}{l}259 \text { estudantes } \\
\text { matriculados } \\
\text { em todos os pe- } \\
\text { ríodos do Curso } \\
\text { de Ciências } \\
\text { Contábeis de } \\
\text { uma institui- } \\
\text { ção de ensino } \\
\text { superior pública } \\
\text { brasileira. }\end{array}$ & $\begin{array}{l}\text { Quanti- } \\
\text { tativo }\end{array}$ \\
\hline
\end{tabular}


Fonte: Dados da pesquisa, 2016.

Como pode ser observado no Quando 1, três dos 5 estudos tiveram uma abordagem quantitativa (JOLY; PRATES, 2011; RUFINI; BZUNECK; OLIVEIRA, 2011; LEAL; MIRANDA; CARMO, 2013), sendo os 2 primeiros mais voltados para análise ou validação de medidas de avaliação. Entre os estudos qualitativos, um se utilizou da etnometodologia (BRAMBILLA; DAMACENA, 2012) e o outro trabalhou, essencialmente, com a realização de observações exploratórias (MACHADO et al, 2012).

Nenhum dos estudos recentes listados contemplou o universo da pós-graduação, 2 deles foram aplicados ao ensino fundamental (RUFINI; BZUNECK; OLIVEIRA, 2011; MACHADO et al, 2012) e 3 ao ensino superior (JOLY; PRATES, 2011; BRAMBILLA; DAMACENA, 2012; LEAL; MIRANDA; CARMO, 2013).

Por fim, verificou-se que apenas o estudo de Leal, Miranda e Carmo (2013) teve como aspecto central a avaliação da motivação dos estudantes à luz da Teoria da Autodeterminação.

\section{Procedimentos metodológicos}

O presente estudo é caracterizado por ser dedutivo, pois parte de premissas da teoria da autodeterminação para sustentar suas conclusões, descritivo porque expõe características do processo motivacional dos grupos de mestres pesquisados e de corte transversal uma vez que a coleta de informações junto aos mestres participantes da pesquisa foi realizada somente uma vez (MARCONI; LAKATOS, 2003; VIEIRA, 2004; VERGARA, 2011).

Nessa perspectiva, foi adotado um enfoque analítico qualitativo, tendo como plano básico de pesquisa o estudo comparativo, no qual "não se observa o caso como um todo, nem toda sua complexidade; em vez disso observa-se a multiplicidade de casos relacionados a determinados excertos" (FLICK, 2009, p. 135).

A postura teórica adotada para compreender o objeto de estudo e estabelecer o foco metodológico da pesquisa foi o interacionismo simbólico. Segundo Flick (2009, p. 69), na tradição do interacionismo simbólico, "o ponto de partida empírico consiste no significado subjetivo atribuído pelos indivíduos a suas atividades e ambien- 
tes". Nesse sentido, essa suposição teórica "focaliza a natureza das interações, a dinâmica das atividades sociais entre as pessoas, os significados que elas atribuem aos eventos, os ambientes naturais em que vivem e as ações que desempenham" (SILVA et al, 2013, p. 2).

Dessa forma, a estratégia da pesquisa foi estabelecida para compreender o processo motivacional para conclusão dos cursos de mestrado acadêmico e profissional em Administração, a partir da percepção dos próprios mestres oriundos desses cursos.

Quanto à sua abrangência este estudo foi realizado com mestres oriundos de uma turma de mestrado acadêmico e de uma turma de mestrado profissional da Universidade Federal do Rio Grande do Norte (UFRN). Ambas as turmas pertenciam a programas de pósgraduação ligados ao Centro de Ciências Sociais Aplicadas (CCSA).

A turma de mestrado acadêmico pesquisada teve ingresso no ano de 2012 no Programa de Pós-Graduação em Administração (PPGA) com um total de 18 alunos matriculados. No caso da turma de mestrado profissional, o ingresso ocorreu no segundo semestre de 2011 também no PPGA com 33 alunos matriculados. Apesar da turma de mestrado profissional ter iniciado vinculada ao PPGA, no decorrer do curso ocorreu à migração para o Programa de PósGraduação em Gestão Pública (PPGP/UFRN).

Assim, a pesquisa foi composta por 6 mestres, sendo 3 oriundos do mestrado acadêmico e 3 do profissional. Tanto o grupo do mestrado acadêmico como o do mestrado profissional foram constituídos por dois homens e uma mulher cada, sendo que a média de idade do mestrado profissional foi de 41,3 anos, superior à do mestrado acadêmico, que foi de 27,3 anos. No que se refere à formação dos entrevistados, o grupo do mestrado acadêmico foi mais homogêneo com dois administradores e um engenheiro de produção, já o grupo do mestrado profissional se mostrou mais heterogêneo, inclusive com indivíduos com mais de uma graduação, tendo apenas um administrador. O perfil dos entrevistados está resumido no Quadro 2. 
Quadro 02 - Perfil dos entrevistados.

\begin{tabular}{|l|l|l|l|l|}
\hline Tipo de Curso & $\begin{array}{l}\text { Nome } \\
\text { Fictício }\end{array}$ & Sexo & Idade & Graduação \\
\hline \multirow{4}{*}{$\begin{array}{l}\text { Mestrado } \\
\text { acadêmico }\end{array}$} & Emanoel & Masculino & 32 anos & $\begin{array}{l}\text { Engenharia da } \\
\text { produção }\end{array}$ \\
\cline { 2 - 5 } & Pedro & Masculino & 24 anos & Administração \\
\cline { 2 - 5 } & Sônia & Feminino & 26 anos & Administração \\
\hline \multirow{4}{*}{$\begin{array}{l}\text { Mestrado } \\
\text { profissional }\end{array}$} & Assis & Masculino & 41 anos & $\begin{array}{l}\text { Direito e } \\
\text { Economia }\end{array}$ \\
\cline { 2 - 5 } & Francisca & Feminino & 49 anos & $\begin{array}{l}\text { Psicologia e } \\
\text { Economia }\end{array}$ \\
\cline { 2 - 5 } & Hélio & Masculino & 34 anos & Administração \\
\hline
\end{tabular}

Fonte: Dados da pesquisa, 2016.

A estrutura de coleta foi definida a priori e o critério de seleção dos participantes foi o de conveniência, dessa forma, os pesquisadores verificaram os mestres mais acessíveis e que pudessem participar das entrevistas. Mesmo tendo uma escolha dos entrevistados definida antecipadamente, há indícios de que se alcançou a saturação teórica, já que não foi agregado nenhum código novo a partir da quinta entrevista. De acordo com Flick (2009, p. 121), a a definição dos participantes do estudo e a "integração de outros materiais são concluídas quando a 'saturação teórica' de uma categoria ou grupo de casos tenha sido atingida (ou seja, quando não surgir mais nada novo)".

Os dados da pesquisa foram coletados no mês de março de 2015, por meio de entrevistas realizadas em locais diversos, de acordo com a preferência e a disponibilidade dos entrevistados. Optou-se pela entrevista do tipo focalizada, na qual "após apresentação de um estímulo uniforme [...], estuda-se o impacto deste sobre o entrevistado a partir da utilização de um guia de entrevista" (FLICK, 2009, p.144). Para promover os estímulos necessários para a realização da entrevista focalizada, foi utilizada a foto-elicitação, um processo colaborativo por meio do qual o pesquisador se torna um ouvinte enquanto o sujeito da pesquisa interpreta as fotografias 
para o entrevistador (MENDONÇA; VIANA, 2007).

No processo de construção da estratégia para coleta de dados foram realizados dois testes pilotos com dois mestres, um deles oriundo do mestrado acadêmico e outro do mestrado profissional. Essa etapa foi essencial para definição da versão final do roteiro de entrevista e do conjunto de imagens escolhidas como estímulos. Além disso, os testes pilotos possibilitaram a uniformização do processo de condução da entrevista, definindo-se a seguinte sequência: a) apresentação do Termo de Consentimento Livre e Esclarecido (TCLE); b) solicitação de autorização para iniciar a gravação da entrevista; c) exposição das imagens, todas de uma só vez, para que o entrevistado escolhesse as 3 principais que representassem a motivação para conclusão do mestrado, sendo as demais desconsideradas no restante da entrevista; e d) aplicação do roteiro de entrevista.

As imagens foram selecionadas no Google Imagens a partir de um processo de busca que utilizou strings baseados em palavras representativas de cada nível de motivação presente no modelo da teoria da autodeterminação (Figura 1). A entrevista foi realizada por dois pesquisadores, sendo um deles destinado a conduzir a entrevista com base no roteiro pré-definido e o outro para fazer as notas de campo relacionadas às percepções obtidas no momento das respostas dadas. As notas de campo constituem um dos meios clássicos de documentação na pesquisa qualitativa (FLICK, 2009) e contribuíram como suporte na etapa de análise dos dados.

Para permitir que os dados oriundos das entrevistas fossem analisados, alguns procedimentos foram adotados a fim de garantir rigor metodológico e a validade da pesquisa. Assim, após a realização da entrevista, as informações foram transcritas considerando as convenções de transcrição adotadas por Flick (2009) e por Gibbs (2009), reforçando desse modo a exigência de uma padronização nesse momento e adoção de normas e representações no texto. Outro tópico importante considerado foi o anonimato dos nomes citados, referências a instituições, órgãos, lugares, sendo substituídos por nomes fictícios, entretanto para viabilização disso, precisou-se criar uma listagem, em arquivo separado, com todos os nomes anonimizados, então ao final gerou-se uma versão anonimizada e outra não. Reforça-se também que não houve substituição de palavras, nem 
correções gramaticais durante essa etapa.

Salienta-se, contudo, que a transcrição foi feita logo após a entrevista realizada pelo entrevistador e só após ouvir a gravação novamente, tendo o texto já transcrito em mãos, foi possível a inserção das normas padronizadas e a observação cautelosa das falas dos entrevistados. Em posse desses dados compilados e para garantir a precisão e fidedignidade das transcrições, foram enviados por e-mail, a todos os entrevistados, os conteúdos transcritos na versão anonimizada juntamente com a legenda e normas seguidas para essa etapa. Os entrevistados não solicitaram alterações nas transcrições enviadas, com isso, após a autorização dos mesmos, a etapa de interpretação dos dados foi iniciada. As transcrições das 6 entrevistas realizadas totalizaram 2 horas, 12 minutos e 36 segundos, resultando em 23 páginas de transcrição. $\mathrm{O}$ tempo médio de entrevista está próximo dos 21 minutos e o número médio de páginas é de 3,8 por entrevista.

Quanto ao método de interpretação dos dados foi utilizada a análise de conteúdo, segundo o modelo de Bardin (2011). Para a autora, tal análise representa "um conjunto de técnicas de análise das comunicações que utiliza procedimentos sistemáticos e objetivos de descrição do conteúdo das mensagens" (BARDIN, 2011, p. 44). Para tanto, essa abordagem está organizada em três fases: 1) a pré-análise; 2) a exploração do material; e 3) o tratamento dos resultados, inferência e interpretação.

A pré-análise foi a fase na qual se organizou o material a ser analisado com o objetivo de torná-lo operacional, sistematizando as ideias iniciais. De forma específica, através dessa etapa, foi possível realizar a leitura e aprofundamento da teoria da autodeterminação e sua correlação com o objetivo da presente pesquisa.

Já na exploração do material, foram realizadas diferentes ações: a primeira consistiu no processo de codificação dos textos oriundos das entrevistas transcritas, o que resultou na formulação de categorias e subcategorias de análises. A segunda foi a busca de unidades de registro, as quais corresponderam ao segmento de conteúdo a considerar como unidade base, visando à contagem das frequências encontradas e, por fim, buscou-se as unidades de contexto, que representaram as unidades de compreensão para codificar a unidade 
de registro; sendo, portanto, o segmento da mensagem, útil para compreender a significação exata da unidade de registro. A seleção dessas unidades de contexto foi realizada na medida em que foram feitas as análises das subcategorias em cada entrevista transcrita.

Nesse sentido, para conclusão dessa etapa da análise de conteúdo, optou-se primeiramente por considerar as categorias advindas da teoria da autoderminação: desmotivação, motivação extrínseca, tendo como subcategorias motivação controlada, moderadamente controlada, moderadamente autônoma, autônoma, e, por último, a categoria de motivação extrínseca. E após isso, com base nas entrevistas já transcritas, desenvolveu-se o processo de codificação.

Para Flick (2009), existem alguns tipos de codificação, seja a teórica, a temática, a análise qualitativa de conteúdo ou a análise global. Então, diante dos critérios e especificações de cada uma delas, verificou-se que a mais coerente com a presente pesquisa foi à análise qualitativa de conteúdo com a técnica de análise estruturadora de conteúdo, por se tratar de um método para interpretação dos dados que tem como característica principal a utilização de categorias essencialmente obtidas por meio de modelos teóricos e por ser utilizado principalmente para a análise dos pontos de vista subjetivos coletados em entrevistas, precisando, contudo, formular regras de codificação, a fim de se buscar nos textos transcritos, os trechos mais relacionados com todas as categorias previamente definidas. Para tanto, tal método se deu por meio da formalização dos procedimentos, com esquema uniforme de categorias, facilitando a comparação dos diferentes casos analisados.

Diante dessa perspectiva, originaram-se códigos, os quais foram relacionados com as categorias e subcategorias da teoria da autodeterminação, sendo necessário revisá-los por 3 (três) vezes durante o processo, a fim de garantir a melhor alocação dos mesmos. Na primeira etapa da codificação foram gerados 24 códigos, contemplando 208 referências textuais. A segunda etapa consistiu em uma revisão de todos os códigos e dos seus relacionamentos com as categorias e subcategorias, dessa forma, o número de códigos foi reduzido para 20 e o número de referências textuais para 206. Por fim, na terceira etapa, os códigos gerados não sofreram alterações, mas optou-se por 
codificar apenas uma referência textual por código por questão de entrevista, o que gerou uma redução na quantidade de referências de 206 para 140.

É importante ressaltar que emergiu do processo de codificação uma nova categoria, intitulada "outras teorias da motivação", haja vista que surgiram trechos que não eram explicados pela teoria da autodeterminação, escolhida como norteadora teórica da pesquisa.

Após isso, pôde-se dar sequência à última fase da análise de conteúdo que foi o tratamento dos resultados, inferência e interpretação, na qual se exige análise reflexiva e crítica. Para auxiliar essa etapa, adotou-se a análise comparativa de Gibbs (2009), a qual considera a hierarquização de codificação e as possibilidades de diferentes tipos de comparações, tendo como principal atributo o tipo de curso dos entrevistados (mestrado acadêmico ou mestrado profissional). Dessa forma, embora também tenha sido realizada uma análise inicial intra-casos, apresentando os resultados gerais por entrevistado, foi privilegiada a análise inter-casos, mais adequada ao objetivo proposto na pesquisa. Ressalta-se que uma "razão fundamental para promover a análise inter-casos é aprofundar a compreensão e a explicação" (MILES; HUBERMAN, 1994, p. 173) das questões discutidas na pesquisa.

Destaca-se, ainda, que a grande quantidade de material anteriormente disponível pelas entrevistas transcritas foi reduzida de forma a permitir que os pesquisadores pudessem obter as respostas e inferências relacionadas ao problema de pesquisa. Esse processo foi viabilizado através da uma ferramenta chamada NVivo, que é um software designado como parte dos softwares QDA (Qualitative Data Analysis) ou CAQDAS (Computer-aided Qualitative Data Analysis Software), os quais são capazes de auxiliar no processo de codificação, armazenamento e interação dos dados.

Por fim, este artigo assegurou os padrões éticos da pesquisa qualitativa e, com vistas ao fortalecimento da transparência, as imagens utilizadas, o roteiro e as transcrições das entrevistas e a estrutura de codificação resultante da pesquisa podem ser disponibilizados mediante solicitação aos autores. 


\section{ANÁlise dos RESUltados}

Conforme descrito nos procedimentos metodológicos deste estudo, foram extraídas do Continuum da autodeterminação (Figura 1), apresentado por Gagné; Deci (2005), as categorias e as subcategorias que nortearam o processo de codificação das entrevistas analisadas. O resumo dessa codificação está descrito na Tabela 2, na qual é possível identificar trechos codificados em todas as categorias e subcategorias propostas com base na teoria da autodeterminação (GAGNÉ; DECI, 2005; GUIMARÃES; BZUNECK, 2008). Adicionalmente, a Tabela 2 também apresenta o quantitativo de trechos codificados na categoria "outras teorias da motivação", que emergiu dos dados, durante o processo de codificação, acomodando códigos relacionados ao processo motivacional dos indivíduos e que não se enquadravam dentro do escopo da teoria da autodeterminação.

Tabela 2 - Resumo da codificação por categorias e subcategorias.

\begin{tabular}{|c|c|c|c|c|c|}
\hline \multirow[b]{2}{*}{ № } & \multirow[b]{2}{*}{ Categorias } & \multirow{2}{*}{$\begin{array}{l}\text { Entre- } \\
\text { vistas } \\
\text { Codifi- } \\
\text { cadas }\end{array}$} & \multicolumn{3}{|c|}{ Trechos codificados } \\
\hline & & & $\begin{array}{l}\text { Mestrado } \\
\text { Acadêmico }\end{array}$ & $\begin{array}{l}\text { Mestrado } \\
\text { Profissional }\end{array}$ & Total \\
\hline 1 & Desmotivação & 3 & 2 & 4 & 6 \\
\hline \multirow[t]{5}{*}{2} & Motivação Extrínseca & 6 & 45 & 47 & 92 \\
\hline & $\begin{array}{l}\text { 2.1. Motivação contro- } \\
\text { lada }\end{array}$ & 5 & 9 & 4 & 13 \\
\hline & $\begin{array}{l}\text { 2.2. Motivação modera- } \\
\text { damente controlada }\end{array}$ & 5 & 6 & 16 & 22 \\
\hline & $\begin{array}{l}\text { 2.3. Motivação modera- } \\
\text { damente autônoma }\end{array}$ & 6 & 13 & 6 & 19 \\
\hline & 2.4. Motivação autônoma & 6 & 17 & 21 & 38 \\
\hline 3 & Motivação Intrínseca & 5 & 8 & 8 & 16 \\
\hline 4 & $\begin{array}{l}\text { Outras teorias da moti- } \\
\text { vação }\end{array}$ & 4 & 9 & 17 & 26 \\
\hline
\end{tabular}

Fonte: Dados da pesquisa, 2016.

A análise do quantitativo de trechos codificados nas categorias 
da teoria da autodeterminação permite constatar que a codificação foi mais prevalente na "motivação extrínseca", seguida da "motivação intrínseca" e, por fim, da "desmotivação", nos dois programas analisados. Houve, contudo, uma divergência quanto à categoria da "motivação extrínseca", visto que, no mestrado acadêmico, a ordem decrescente de codificação seguiu da "motivação autônoma" para a "motivação moderadamente autônoma", enquanto que no profissional, seguiu para a "moderadamente controlada". A categoria "desmotivação", apesar de pouco representativa, esteve presente em três das seis entrevistas analisadas.

Os únicos níveis de motivação identificados nas seis entrevistas foram a "motivação moderadamente autônoma" e a "motivação autônoma", revelando que os mestres oriundos dos mestrados acadêmico e profissional apresentaram um processo motivacional com alto grau de autonomia, no entanto, ainda considerando estímulos internos ou externos. A presença de motivação com grau elevado de autonomia também prevaleceu entre os estudantes de Ciências Contábeis em pesquisa realizada por Leal, Miranda e Carmo (2013, p. 169), na qual foi identificado que "além de motivados para a realização das atividades acadêmicas com perspectivas voltadas para os benefícios pessoais que podem advir de tais atividades, esses alunos têm interesse e prazer na realização daquelas tarefas [...]".

A categoria "desmotivação" foi revelada nas entrevistas analisadas por meio de dois códigos: "pensar em desistir" e "não ter recompensa no trabalho", sendo o primeiro mais prevalente tanto no mestrado profissional quanto no acadêmico, conforme pode ser observado na Tabela 3.

Tabela 3 - Códigos relacionados à categoria "Desmotivação".

\begin{tabular}{|c|c|c|c|c|c|}
\hline \multicolumn{6}{|c|}{ Categoria: Desmotivação } \\
\hline \multirow[b]{2}{*}{ № } & \multirow[b]{2}{*}{ Códigos } & \multirow{2}{*}{$\begin{array}{l}\text { Entrevistas } \\
\text { Codificadas }\end{array}$} & \multicolumn{3}{|c|}{ Trechos codificados } \\
\hline & & & $\begin{array}{l}\text { Mestrado } \\
\text { Acadêmico }\end{array}$ & $\begin{array}{l}\text { Mestrado } \\
\text { Profissional }\end{array}$ & $\begin{array}{l}\text { To- } \\
\text { tal }\end{array}$ \\
\hline 1 & Pensar em desistir & 3 & 2 & 3 & 5 \\
\hline 2 & $\begin{array}{l}\text { Não ter recompen- } \\
\text { sa no trabalho }\end{array}$ & 1 & 0 & 1 & 1 \\
\hline
\end{tabular}


Fonte: Dados da pesquisa, 2016.

Com relação ao número de trechos codificados, o mestrado profissional apresentou maior número de referências textuais. No entanto, é importante ressaltar que todas as referências estão presentes em uma mesma entrevista, no caso, a entrevista de Francisca. As outras referências estão distribuídas em duas entrevistas do mestrado acadêmico. Com isso, percebe-se que a sensação de desmotivação foi mais intensa no caso de Francisca, do mestrado profissional, mas foi mais difundida no mestrado acadêmico.

Como o código mais relevante, que inclui trechos envolvendo os dois grupos pesquisados, foi "pensar em desistir", elaborou-se o Quadro 3 com exemplos de um trecho codificado para cada programa, ilustrando o contexto que envolveu os momentos nos quais os mestres pensaram em desistir.

Quadro 3 - Referências textuais da categoria "Desmotivação".

\begin{tabular}{|l|l|l|}
\hline $\begin{array}{l}\text { Tipo de curso } \\
\text { do Entrevis- } \\
\text { tado }\end{array}$ & $\begin{array}{l}\text { Código } \\
\text { relevante }\end{array}$ & Transcrição \\
\hline $\begin{array}{l}\text { Mestrado aca- } \\
\text { dêmico }\end{array}$ & $\begin{array}{l}\text { Pensar em } \\
\text { desistir }\end{array}$ & $\begin{array}{l}\text { Eu passei os primeiros oito meses sem } \\
\text { bolsa (...). Então, quando eu comecei o } \\
\text { mestrado, ainda sem bolsa, tinha muita } \\
\text { cobrança, entendeu? De, se eu iria traba- } \\
\text { lhar ou não, de ficar sendo sustentado, } \\
\text { Você não vai acabar a faculdade? Você } \\
\text { não vai começar não? Vai trabalhar, ga- } \\
\text { nhar seu dinheiro(Pedro, 2016)! }\end{array}$ \\
\hline $\begin{array}{l}\text { Mestrado pro- } \\
\text { fissional }\end{array}$ & $\begin{array}{l}\text { (...) foram dois momentos que eu pensei } \\
\text { em desistir do mestrado: primeiro foi } \\
\text { durante o problema de saúde (...), vi- } \\
\text { nha assim um desestímulo de continuar } \\
\text { estudando, até porque, como eu disse, } \\
\text { ninguém me cobrava, só quem me cobra- } \\
\text { va pra que eu concluísse era eu mesma } \\
\text { (...) (Assis, 2016). }\end{array}$ \\
\hline
\end{tabular}

Fonte: Dados da pesquisa, 2016.

A leitura dos trechos apresentados no Quadro 3 evidencia a ausência de comportamento proativo dos indivíduos, caracterizando a 
situação de desmotivação (LEAL; MIRANDA; CARMO, 2013; MADJAR, COHEN-MALAYEV, 2013). Fica claro também que tal situação ocorreu em momentos muito particulares de cada mestrando, relacionados com situações adversas pontuais, mas que foram superadas.

Na Tabela 4 identificam-se os resultados para a categoria "motivação extrínseca", na qual segundo o Continuum da autodeterminação (Figura 1) apresentado por Gagné; Deci (2005), foram observadas quatro subcategorias que representam níveis desse tipo de motivação. De uma maneira geral, o maior número de códigos pode ser visualizado no nível da "motivação autônoma", enquanto que o único código que contempla referências dos seis entrevistados está na "motivação moderadamente autônoma" e diz respeito a "exercer profissão ou função fruto do mestrado", algo que se revelou importante para os indivíduos dos dois grupos.

Tabela 4 - Códigos relacionados à categoria "Motivação Extrínseca".

\begin{tabular}{|c|c|c|c|c|c|}
\hline \multicolumn{6}{|c|}{ Categoria: Motivação Extrínseca } \\
\hline \multirow[b]{2}{*}{ № } & \multirow[b]{2}{*}{ Códigos } & \multirow{2}{*}{$\begin{array}{l}\text { Entrevistas } \\
\text { Codificadas }\end{array}$} & \multicolumn{3}{|c|}{ Trechos codificados } \\
\hline & & & $\begin{array}{l}\text { Mestrado } \\
\text { Acadêmico }\end{array}$ & \begin{tabular}{|l|} 
Mestrado \\
Profissional
\end{tabular} & Total \\
\hline \multicolumn{6}{|c|}{ Subcategoria: Motivação controlada } \\
\hline 1 & $\begin{array}{l}\text { Ter melhoria financeira como } \\
\text { recompensa }\end{array}$ & 4 & 7 & 2 & 9 \\
\hline 2 & Sofrer punição & 4 & 2 & 2 & 4 \\
\hline \multicolumn{6}{|c|}{ Subcategoria: Motivação moderadamente controlada } \\
\hline 1 & Cobrar a si mesmo & 4 & 3 & 11 & 14 \\
\hline 2 & $\begin{array}{l}\text { Ter medo quanto ao sucesso da } \\
\text { tarefa }\end{array}$ & 3 & 1 & 3 & 4 \\
\hline 3 & Sentir-se culpado & 2 & 0 & 4 & 4 \\
\hline \multicolumn{6}{|c|}{ Subcategoria: Motivação moderadamente autônoma } \\
\hline 1 & $\begin{array}{l}\text { Exercer profissão ou função fruto } \\
\text { do mestrado }\end{array}$ & 6 & 11 & 4 & 15 \\
\hline 2 & $\begin{array}{l}\text { Ter conhecimento como instru- } \\
\text { mento para conquistas }\end{array}$ & 2 & 2 & 2 & 4 \\
\hline \multicolumn{6}{|c|}{ Subcategoria: Motivação autônoma } \\
\hline 1 & Ser exemplo & 2 & 5 & 0 & 5 \\
\hline 2 & Agir para alcançar um objetivo & 5 & 7 & 7 & 14 \\
\hline 3 & Obter reconhecimento & 4 & 5 & 3 & 8 \\
\hline 4 & Ter conhecimento como valor & 5 & 6 & 5 & 11 \\
\hline
\end{tabular}


Fonte: Dados da pesquisa, 2016.

Passando a analisar cada uma das subcategorias, verifica-se que a primeira subcategoria foi a da "motivação controlada", que de acordo com Guimarães e Bzuneck (2008); Ferguson et al (2015). consiste no nível menos autônomo da motivação humana, a qual está ligada às possibilidades de punições e recompensas que um indivíduo pode sofrer caso não exerça determinada atividade. $\mathrm{Na}$ referida categoria, observa-se uma maior frequência no código "ter melhoria financeira como recompensa", sendo essa frequência mais acentuada no mestrado acadêmico. Tal resultado pode ser justificado pelo fato dos egressos advindos do mestrado profissional já desenvolverem atividade remunerada, inclusive com estabilidade, já que são servidores efetivos do Estado.

Em uma visão oposta à recompensa financeira, identificou-se uma frequência equivalente entre mestrado acadêmico e mestrado profissional no que diz respeito ao código "sofrer punição", o que está relacionado às características do convênio gerador do curso de mestrado profissional, que previa ressarcimento ao erário dos valores investidos nos mestrandos em caso de não conclusão, e também à possibilidade de devolução de bolsas no mestrado acadêmico.

A segunda subcategoria consiste na "motivação moderadamente controlada", que, conforme Guimarães e Bzuneck (2008); Moran (2012), está relacionada às pressões internas que o próprio indivíduo exerce em busca do cumprimento da tarefa. É a autocrítica exercendo um papel fundamental na definição do comportamento motivado do indivíduo em busca do seu objetivo. Destacam-se os códigos identificados na análise de conteúdo que estão relacionados a "cobrar a si mesmo", "ter medo quanto ao sucesso da tarefa" e "sentir-se culpado". Dentre estes códigos é importante observar a frequência apresentada para o "cobrar a si mesmo", ao qual se identificou 14 trechos codificados, tendo um maior destaque o mestrado profissional. Nessa linha de análise observa-se ainda uma maior tendência dos mestrandos egressos do mestrado profissional em apresentarem uma elevada frequência em relação aos outros códigos desta subcategoria, quando comparados com os egressos do mestrado acadêmico.

Quanto à "motivação moderadamente autônoma", destaca- 
se uma forte relação entre elementos externos e internos, que são geradores do comportamento motivado, desta forma, podem-se observar as razões instrumentais que levam um individuo a exercer determinada profissão, relacionando-se com elementos de maior autonomia e emancipação como o ser humano em busca da sua realização profissional (LENS, MATOS E VANSTEENKISTE, 2008). Destacam-se dois códigos que emergiram desta subcategoria da motivação extrínseca, que são o "exercer profissão ou função fruto do mestrado" e o "ter conhecimento como instrumento para conquistas", o que permite observar uma maior frequência de trechos codificados para o exercício da função fruto do mestrado, tendo sido gerado uma maior quantidade de trechos codificados para o mestrado acadêmico, o que se justifica pelas características dos alunos do mestrado profissional, que já atuavam profissionalmente como servidores públicos e, na maioria das vezes, não identificavam oportunidades de crescimento dentro da carreira no Estado.

O nível de "motivação autônoma" destaca-se por apresentar o maior grau de liberdade de ação do indivíduo, todavia segundo Rufini, Bzuneck e Oliveira (2011), essa subcategoria motivacional apesar de proporcionar uma grande autonomia ao agir motivado, ainda possui elementos de regulação externa dando sentido ao comportamento. Assim, observa-se nos resultados um equilíbrio entre os indivíduos pertencentes aos dois programas de mestrado, no qual se destacam os códigos "agir para alcançar objetivos" e "ter conhecimento como valor". Os códigos em destaque nesse nível de motivação estão relacionados a aspectos culturais e simbólicos dos indivíduos estudados, os valores familiares estiveram muito presentes nas falas, bem como a necessidade de adquirir o conhecimento como um objetivo de vida, sendo esta uma busca contínua.

Os resultados da Tabela 4 indicam ainda uma presença frequente da "motivação moderadamente autônoma" no mestrado acadêmico, fato corroborado pelos resultados obtidos no Quadro 4, que evidencia a seleção de códigos relevantes de acordo com cada grupo analisado. 
Quadro 4 - Referências textuais da categoria "Motivação Extrínseca".

\begin{tabular}{|l|l|l|}
\hline $\begin{array}{l}\text { Tipo de curso } \\
\text { do Entrevistado }\end{array}$ & $\begin{array}{l}\text { Código } \\
\text { relevante }\end{array}$ & Transcrição \\
\hline $\begin{array}{l}\text { Mestrado acadê- } \\
\text { mico }\end{array}$ & $\begin{array}{l}\text { Exercer pro- } \\
\text { fissão ou } \\
\text { funão fruto } \\
\text { do mestrado } \\
\text { Motivação } \\
\text { moderadamen- } \\
\text { te autônoma) }\end{array}$ & $\begin{array}{l}\text { (...) vem da vontade também de ser } \\
\text { professora. Então eu acho que é (...) } \\
\text { onde o seu objetivo final é se tornar } \\
\text { mestre. Acho que é ensinar (Sônia, } \\
\text { 2016). }\end{array}$ \\
\hline $\begin{array}{l}\text { Mestrado Profis- } \\
\text { sional }\end{array}$ & $\begin{array}{l}\text { Cobrar a si } \\
\text { mesmo (Moção mo- } \\
\text { tivaradamente } \\
\text { derantrolada) }\end{array}$ & $\begin{array}{l}\text { Eu acho que o determinante era eu } \\
\text { mesma me cobrar, assim eu con- } \\
\text { cluir, eu acabar o que eu começo. } \\
\text { Questão de (...) Eu sou orgulhosa, } \\
\text { eu gosto de concluir o que eu faço } \\
\text { (Francisca, 2016). }\end{array}$ \\
\hline
\end{tabular}

Fonte: Dados da pesquisa, 2016.

Pode ser observado no trecho da fala de um dos entrevistados do mestrado acadêmico que um dos motivos que o levou a concluir o seu mestrado foi a vontade de ser professora, demonstrando em seu comportamento motivado uma significativa influência da vontade de atuar profissionalmente como docente, gerando estímulos motivacionais moderadamente autônomos, sendo o "se ver atuando como professora" um dos condicionantes ao comportamento para concluir o curso. Já no mestrado profissional, observa-se uma influência da "motivação moderadamente controlada", com destaque no Quadro 4 ao trecho da transcrição que apresenta autocobrança, o desafio de terminar uma atividade iniciada como um forte indutor do comportamento motivado.

O nível de maior autonomia do comportamento motivado apresentado pela teoria da autodeterminação está na categoria denominada de "motivação intrínseca" que, segundo Bzuneck e Guimarães (2007); Ferguson et al, (2015), permite ao indivíduo exercer o seu comportamento de forma autônoma inerente, tendo o sujeito da ação liberdade para exercê-la livre de influências externas, gerando a emancipação do indivíduo. 
Assim, destacam-se dois códigos identificados nas transcrições que estão relacionados ao "sentir-se bem com a realização da tarefa" e o "buscar o conhecimento". Conforme descrito na Tabela 5, ambos os códigos foram identificados com a mesma frequência tanto no mestrado profissional quanto no mestrado acadêmico, o que demonstra que estes sujeitos apresentam elementos geradores do seu comportamento, que vão além de conquistas instrumentais, mas são inerentes à sua condição como indivíduo em busca da emancipação e servindo, consequentemente, como estímulos para concluir o mestrado.

Tabela 5 - Códigos relacionados à categoria "Motivação Intrínseca".

\begin{tabular}{|c|c|c|c|c|c|}
\hline \multicolumn{6}{|c|}{ Categoria: "Motivação Intrínseca" } \\
\hline \multirow[b]{2}{*}{ № } & \multirow[b]{2}{*}{ Códigos } & \multirow{2}{*}{$\begin{array}{l}\text { Entrevistas } \\
\text { Codificadas }\end{array}$} & \multicolumn{3}{|c|}{ Trechos codificados } \\
\hline & & & $\begin{array}{l}\text { Mestrado } \\
\text { Acadêmico }\end{array}$ & \begin{tabular}{|l|} 
Mestrado \\
Profissional
\end{tabular} & Total \\
\hline 1 & $\begin{array}{l}\text { Sentir-se bem com a } \\
\text { realização da tarefa }\end{array}$ & 3 & 4 & 4 & 8 \\
\hline 2 & $\begin{array}{l}\text { Buscar o conheci- } \\
\text { mento }\end{array}$ & 4 & 4 & 4 & 8 \\
\hline
\end{tabular}

Fonte: Dados da pesquisa, 2016.

Esse nível de emancipação pode ser confirmado ao se observar nos trechos transcritos no Quadro 5, que as falas destacadas estão relacionadas ao código de "buscar o conhecimento". Assim, pode-se observar que essa autonomia se deu por questões inerentes a cada um dos sujeitos pesquisados, no qual se destaca o "prazer" em aprender e desenvolver conhecimento (FERGUSON et al, 2015). 
Quadro 5 - Referências textuais da categoria "Motivação Intrínseca".

\begin{tabular}{|l|l|l|}
\hline $\begin{array}{l}\text { Tipo de curso do } \\
\text { Entrevistado }\end{array}$ & $\begin{array}{l}\text { Código } \\
\text { Relevante }\end{array}$ & Transcrição da entrevista \\
\hline $\begin{array}{l}\text { Mestrado acadê- } \\
\text { mico }\end{array}$ & $\begin{array}{l}\text { Buscar o } \\
\text { conheci- } \\
\text { mento }\end{array}$ & $\begin{array}{l}\text { (...) o prazer que eu tenho de mi- } \\
\text { nistrar aula ou de ser professor ele } \\
\text { advém dessa minha sede, digamos } \\
\text { assim de estudar, de cada dia mais } \\
\text { estar aprendendo de estar desen- } \\
\text { volvendo os meus conhecimentos } \\
\text { (Emanoel, 2016). }\end{array}$ \\
\hline $\begin{array}{l}\text { Mestrado Profis- } \\
\text { sional }\end{array}$ & $\begin{array}{l}\text { Buscar o } \\
\text { conheci- } \\
\text { mento }\end{array}$ & $\begin{array}{l}\text { (...) o conhecimento de uma forma } \\
\text { geral, aonde eu tiver oportunidade } \\
\text { de busca-lo, eu vou buscar, eu vou } \\
\text { trabalhar, eu vou me esforçar (Hé- } \\
\text { lio, 2016). }\end{array}$ \\
\hline
\end{tabular}

Fonte: Dados da pesquisa, 2016.

Os trechos relacionados com a "motivação intrínseca", tanto no mestrado acadêmico como no mestrado profissional, revelam que, para esses indivíduos, o processo ou o caminho de busca pelo conhecimento é tão importante quanto o seu fim, ao alcançar o objetivo traçado. Com isso, fica nítido que a atividade de busca pelo conhecimento torna-se um fim em si mesma.

Além das categorias discutidas no construto da teoria da autodeterminação nos tópicos anteriores, identificaram-se alguns códigos que não foram classificados dentro das subcategorias do Continuum da autodeterminação (Figura 1), resultando na criação da categoria “outras teorias da motivação". Na Tabela 6, observa-se que essa categoria contou com 5 códigos, sendo mais relevante para o grupo do mestrado profissional. 
Tabela 6 - Códigos relacionados à dimensão "Outras teorias da motivação".

\begin{tabular}{|c|c|c|c|c|c|}
\hline \multicolumn{6}{|c|}{ Dimensão: "Outras teorias da motivação" } \\
\hline \multirow[b]{2}{*}{ № } & \multirow[b]{2}{*}{ Códigos } & \multirow{2}{*}{$\begin{array}{l}\text { Entrevistas } \\
\text { Codificadas }\end{array}$} & \multicolumn{3}{|c|}{ Trechos codificados } \\
\hline & & & $\begin{array}{l}\text { Mestrado } \\
\text { Acadêmico }\end{array}$ & \begin{tabular}{|l|} 
Mestrado \\
Profissional \\
\end{tabular} & $\begin{array}{l}\text { To- } \\
\text { tal }\end{array}$ \\
\hline 1 & $\begin{array}{l}\text { Contar com o apoio } \\
\text { de outras pessoas }\end{array}$ & 4 & 2 & 8 & 10 \\
\hline 2 & $\begin{array}{l}\text { Receber críticas de } \\
\text { outras pessoas }\end{array}$ & 3 & 1 & 3 & 4 \\
\hline 3 & $\begin{array}{l}\text { Ter pessoas como } \\
\text { exemplo }\end{array}$ & 3 & 3 & 2 & 5 \\
\hline 4 & $\begin{array}{l}\text { Ter responsabilidade } \\
\text { societal }\end{array}$ & 2 & 1 & 2 & 3 \\
\hline 5 & $\begin{array}{l}\text { Ter um ambiente } \\
\text { amigável }\end{array}$ & 3 & 2 & 2 & 4 \\
\hline
\end{tabular}

Fonte: Dados da pesquisa, 2016.

Entre os códigos da nova categoria destacam-se o "contar com apoio de outras pessoas" e o "ter pessoas como exemplo". Para o primeiro pode-se observar uma maior frequência de códigos gerados para o mestrado profissional, o que demonstra a construção de um ambiente mais aberto a interação, com um clima de cooperação entre os seus componentes. No código "ter pessoas como exemplo" identificou-se uma maior frequência junto ao mestrado acadêmico, o que está relacionado ao processo de envolvimento aluno-professor, que pareceu ser mais comum no mestrado acadêmico, uma vez que parte do seu público é de alunos oriundos da iniciação científica, que verticalizam sua formação na mesma instituição, e acabam tomando seus professores como exemplo. O Quadro 6 apresenta exemplos de trechos para cada um desses códigos. 
Quadro 6 - Referências textuais da categoria "Outras teorias motivacionais".

\begin{tabular}{|l|l|l|}
\hline $\begin{array}{l}\text { Tipo de curso do } \\
\text { Entrevistado }\end{array}$ & $\begin{array}{l}\text { Código rele- } \\
\text { vante }\end{array}$ & Transcrição da entrevista \\
\hline $\begin{array}{l}\text { Mestrado acadê- } \\
\text { mico }\end{array}$ & $\begin{array}{l}\text { Ter pessoas } \\
\text { como exem- } \\
\text { plo }\end{array}$ & $\begin{array}{l}\text { Visualizar, assim, eu visualizei por } \\
\text { intermédio de outras pessoas, é: na } \\
\text { fala de professores que motivam } \\
\text { você a estudar, fazer artigo, a fazer } \\
\text { um bom trabalho para que no final } \\
\text { você publique, na fala de pessoas que } \\
\text { participavam de congressos, que esses } \\
\text { tinham trabalhos elogiados, o pessoal } \\
\text { que começava a ensinar e ir pra sala } \\
\text { de aula (Emanoel, 2016). }\end{array}$ \\
\hline $\begin{array}{l}\text { Mestrado Profis- } \\
\text { sional }\end{array}$ & $\begin{array}{l}\text { Contar com } \\
\text { o apoio de } \\
\text { outras pes- } \\
\text { soas }\end{array}$ & $\begin{array}{l}\text { marcado que é gostaria de deixar a questão do espírito } \\
\text { de grupo da turma, espírito de equi- } \\
\text { pe, a unidade, todo mundo imbuído, } \\
\text { todo mundo ajudando, se ajudando, } \\
\text { ajudando aos outros, todo mundo } \\
\text { envolvido, todo mundo abrindo mão } \\
\text { um pouco de cada coisa, do seu final } \\
\text { de semana, do seu convívio com a } \\
\text { família e ninguém falava em desistir, } \\
\text { ninguém ficava reclamando que tava, } \\
\text { entendeu (Hélio, 2016)? }\end{array}$ \\
\hline
\end{tabular}

Fonte: Dados da pesquisa, 2016.

No trecho que exemplifica o código "ter pessoas como exemplo", no mestrado acadêmico, fica clara a importância e a influência que o contato com o professor e suas experiências acadêmicas gera no aluno. Quanto ao trecho aplicado como exemplo do código "contar com o apoio de outras pessoas", para o mestrado profissional, se sobressai o papel da turma como um importante estímulo motivacional.

Com a conclusão das análises agregadas, promove-se aqui uma discussão intra-casos como forma de auxiliar na compreensão e na ampliação dos resultados inter-casos. Nesse sentido, a Figura 3 apresenta os níveis de motivação que foram detectados por meio de referências codificadas nas entrevistas de cada indivíduo. 
No grupo do mestrado acadêmico, Emanoel apresentou, principalmente, níveis de motivação com grau de autonomia mais elevado, embora também tenha apresentado o nível de motivação mais básico. Pedro navegou da desmotivação à motivação intrínseca e trouxe elementos também de outras teorias da motivação, passando, assim, por todas as categorias apontadas na pesquisa. Já Sônia também teve momentos de desmotivação, mas não apresentou relatos que remetessem à motivação intrínseca.

Figura 3 - Níveis de motivação por indivíduo (quantidade de referências codificadas).

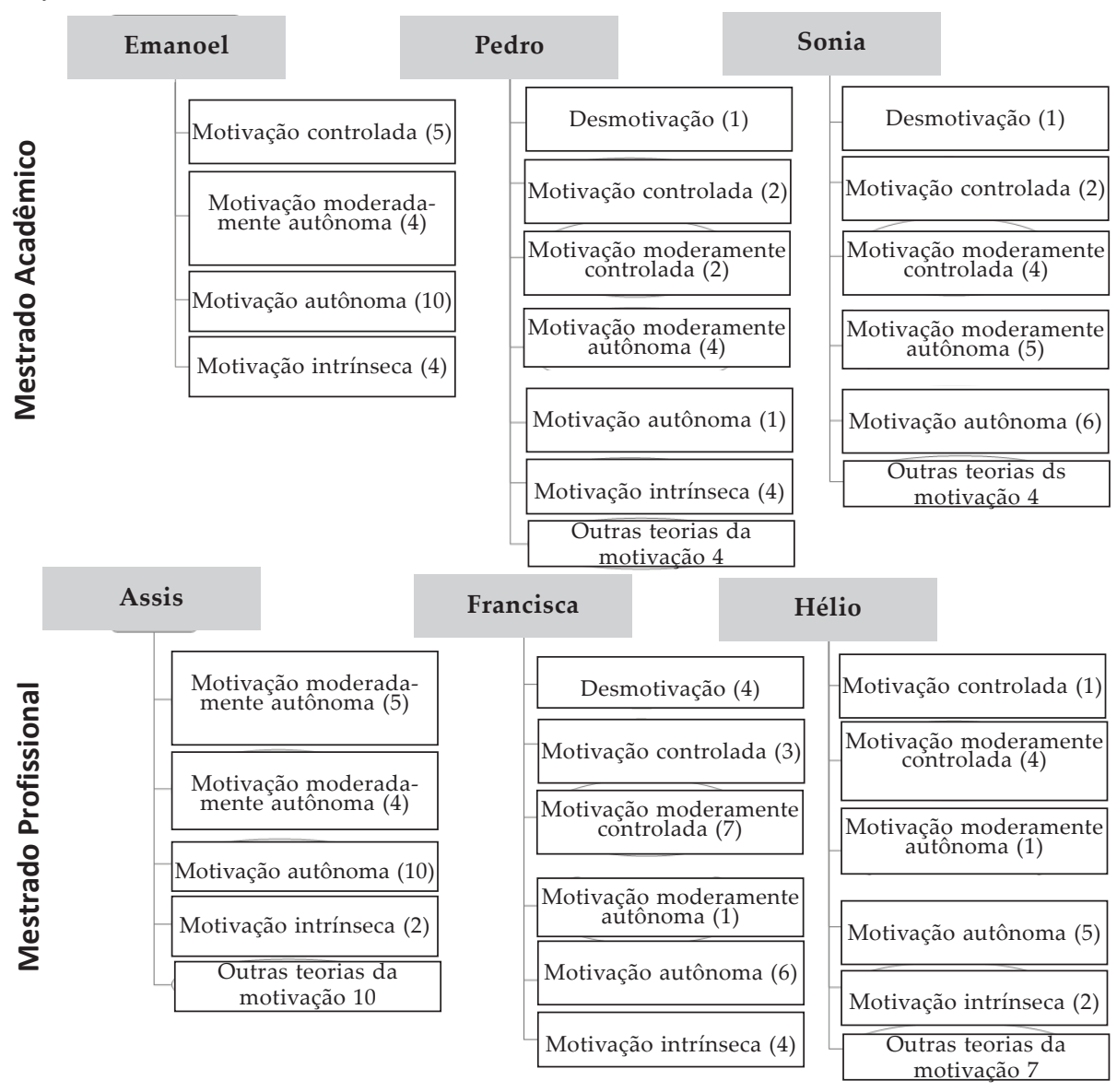

Fonte: Dados da pesquisa, 2016. 
Dentro do mestrado profissional, Assis, assim como Emanoel do acadêmico, mostrou um nível de motivação mais autônomo e teve parte relevante de suas falas codificadas em outras teorias da motivação. Francisca apresentou um processo motivacional que contemplou todas as categorias do Continuum da autodeterminação (Figura 1), mas não revelou aspectos de outras teorias da motivação. Por fim, Hélio teve indícios em todas as categorias, com exceção da desmotivação.

\section{CONSIDERAÇões FINAIS}

As motivações, de acordo com a teoria da autodeterminação, podem variar de forma crescente, desde a desmotivação, passando pela motivação extrínseca até atingir a motivação intrínseca, que seria a forma de maior autonomia individual relacionada à motivação para concluir o mestrado. Tal abordagem teórica, quando utilizada para avaliar comparativamente dois programas de pós-graduação, precisou ser complementada por outras teorias, a fim de abarcar todos os códigos gerados das entrevistas.

Os mestrados profissional e acadêmico demonstraram que existem em ambos a mesma sequência motivacional, partindo da motivação extrínseca, depois a motivação intrínseca e por fim a desmotivação. Entretanto, as análises permitiram evidenciar que de forma divergente entre os programas analisados, na motivação extrínseca, no mestrado acadêmico predominou o tipo moderadamente autônomo, com evidência para o código "exercer profissão fruto do mestrado", enquanto que no profissional prevaleceu a motivação moderadamente controlada, com predomínio para o código de "cobrar a si mesmo". Assim, a motivação para os mestres oriundos do mestrado acadêmico vai ao encontro às oportunidades provenientes da conclusão do mestrado, enquanto que no profissional, a cobrança individual seria algo decisivo para que houvesse motivação (MADJAR; COHEN-MALAYEV, 2013). Os únicos níveis de motivação identificados nas seis entrevistas foram a "motivação moderadamente autônoma" e a "motivação autônoma", revelando que os mestres oriundos dos mestrados acadêmico e profissional apresentaram um processo motivacional com alto grau de autonomia, no entanto, ainda considerando estímulos internos ou externos (JANG; KIM; REEVE, 2012). 
Outro ponto, relevante na análise foi a constatação da importância de outras teorias para explicar a motivação, principalmente, do mestrado profissional, que o apoio de outras pessoas é relevante para que exista a motivação, especialmente nesse tipo de programa. Além disso, embora não tenha emergido da codificação aspectos de competição no mestrado acadêmico, o mestrado profissional revelou evidências empíricas que apontam para um ambiente mais colaborativo (LEAL; MIRANDA; DE NAEGHEL, 2012).

Diante desses resultados, ressalta-se como implicações gerenciais do presente artigo que a teoria da autodeterminação apresenta elementos que podem ser incorporados aos processos seletivos dos programas de pós-graduação em administração, tornando-os mais eficazes na definição do perfil dos candidatos, seja do mestrado acadêmico ou profissional (SCHUNK,1991; MITCHELL JR, 1992; SHEN, 2014; KELLY; SHOGREN, 2014). Além disso, revela categorias que favorecem o incentivo motivacional focalizado no tipo de programa, para que haja a formulação de estratégias motivacionais que diminuam as taxas de desligamento e abandono durante o mestrado (WECHSLER, 2006; LEAL; MIRANDA; DE NAEGHEL, 2012; MADJAR, COHEN-MALAYEV, 2013; MENDONÇA NETO; VIEIRA; OYADOMARI, 2019).

A; DE NAEGHEL, 2012; MADJAR, COHEN-MALAYEV, 2013).

Ademais, as contribuições do trabalho, extrapolaram o campo social, pois do ponto de vista metodológico, abordou-se de forma integrada uma pesquisa à luz da teoria da autodeterminação com análise de conteúdo realizada com auxílio do software NVivo e quanto ao campo empírico, explorou um lócus de pesquisa antes não explorado, o de pós graduação, de forma comparativa entre o mestrado acadêmico e profissional.

Entre as limitações enfrentadas na pesquisa, destacam-se a indisponibilidade de dados consolidados da Capes para índices de abandono na pós-graduação, o que auxiliaria na discussão geral; ausência de estudos recentes com a mesma abordagem, que possibilitassem a comparação entre resultados; o fato de o mestrado profissional ter tido apenas uma turma formada, impossibilitando a análise de mais turmas, em diferentes períodos. 
Para pesquisas futuras, sugere-se a incorporação na análise de outras turmas de mestrado acadêmico e mestrado profissional, permitindo uma análise em diferentes períodos de tempo que pode auxiliar na consolidação da caracterização do processo motivacional de cada grupo. Ressalta-se que o método aplicado neste estudo pode ser replicado para análises em outras áreas do conhecimento, além da Administração.

\section{REFERÊNCIAS}

BARDIN, L. Análise de conteúdo. São Paulo: Edições 70, 2011.

BZUNECK, J.; GUIMARÃES, S. R. Estilos de professores na promoção da motivação intrínseca: reformulação e validação de instrumento. Psicologia: teoria e pesquisa, v. 23, n. 4, p. 415-422, out/dez. 2007.

COORDENAÇÃO DE APERFEIÇOAMENTO DE PESSOAL DE NÍVEL SUPERIOR (CAPES). Plano Nacional de pós-graduação - PNPG 2011-2020 / Coordenação de Pessoal de Nível Superior. Brasília, DF: CAPES, 2010.

COORDENAÇÃO DE APERFEIÇOAMENTO DE PESSOAL DE NÍVEL SUPERIOR (CAPES). Documento de área 2013:administração, ciências contábeis e turismo. Disponível em: <http:// capes.gov.br/images/stories/download/avaliacaotrienal/Docs_de_area/Administra\%C3\%A7\%C3\%A3o_doc_area_e_comiss\%C3\%A3o_16out.pdf >. Acesso em: 6 dez. 2014.

DECI, E. L.; RYAN, R. M. Motivation and self-determination in human behavior. New York: Plenum Press, 1985.

DECI, Edward L.; VANSTEENKISTE, Maarten.Self-determination theory and basic need satisfaction: understanding human development in positive psychology. Ricerche di Psicologia, v. 27, n. 1, 2004.

DE NAEGHEL, J. et al. The relation between elementary students' recreational and academic reading motivation, reading frequency, engagement, and comprehension: A self-determination theory perspective. Journal of Educational Psychology, v. 104, n. 4, 2012.

FERGUSON, R. et al. Self-determination theory, social media and charitable causes: An indepth analysis of autonomous motivation. European Journal of Social Psychology, v. 45, n. 3, p. 298-307, 2015.

FLICK, U. Introdução à pesquisa qualitativa. 3. ed. Porto Alegre: Artmed, 2009. .

GAGNÉ, M.; DECI, E. L. Self-determination theory and work motivation. Journal of Organizational Behavior, v. 26, p. 331-362, 2005.

GIBBS, G. Análise de dados qualitativos. Porto Alegre: Bookman, 2009.

GUIMARÃES, S. É.; BORUCHOVITCH, Evely; o estilo motivacional do professor e a motivação intrínseca dos estudantes: uma perspectiva da Teoria da Autodeterminação. Psicologia: Reflexão e Crítica, v. 17, n. 2, p. 150, 2004. 
GUIMARÃES, S. É.; BZUNECK, José Aloyseo. Propriedades psicométricas de um instrumento para a avaliação da motivação de universitários. Ciência e Cognição, v. 13, n. 1, p. 101-113, 2008.

JANG, H.; KIM, E. J.; REEVE, J. Longitudinal test of self-determination theory's motivation mediation model in a naturally occurring classroom context. Journal of Educational Psychology, v. 104, n. 4, p. 1175, 2012.

JOLY, M. C. R. A.; PRATES, E. A. R. Avaliação da escala de motivação acadêmica em estudantes paulistas: propriedades psicométricas. Psico-USF, v. 16, n. 2, p. 175, 2011.

LEAL, E. A.; MIRANDA, G. J.; CARMO, C. R. S. Teoria da Autodeterminação: uma análise da motivação dos estudantes do curso de Ciências Contábeis. Revista de Contabilidade e Finanças, v. 24, n. 62, p. 162-173, mai./ago. 2013.

LENS, W.; MATOS, L.; VANSTEENKISTE, M. Professores como fontes de motivação dos alunos: o quê e o porquê da aprendizagem do aluno. Educação, v. 31, n. 1, p, 17-20, jan./abr. 2008.

LOBOS, J. Teorias sobre a motivação no trabalho. Revista Administração de Empresa - RAE, v. 15, n. 2 , p. $17-25,1975$.

KELLY, J. R.; SHOGREN, K. A. The impact of teaching self-determination skills on the on-task and off-task behaviors of students with emotional and behavioral disorders. Journal of Emotional and Behavioral Disorders, v. 22, n. 1, p. 27-40, 2014.

MACHADO, A. C. T. A. et. al. Estilos motivacionais de professores: preferência por controle ou por autonomia. Psicologia: Ciência e Profissão, v. 32, n. 1, p. 188-210, 2012.

MADJAR, N.; COHEN-MALAYEV, M. Youth movements as educational settings promoting personal development: Comparing motivation and identity formation in formal and non-formal education contexts. International Journal of Educational Research, v. 62, p. 162-174, 2013.

MARCONI, M. de A.; LAKATOS, E. M. Fundamentos de metodologia científica. 5. ed. São Paulo: Atlas, 2003.

MAYER, J.; FABER, M.; XU, X. Seventy-five years of motivation measures (1930-2005): a descriptive analysis. Motivation and Emotion, v. 31, n. 2, p. 83-103, 2007.

MENDONÇA, J. R. C. de; VIANA, M. F. T. Entrevista com Foto-Elicitação (EFE): o uso de métodos visuais para o estudo do ambiente físico nas organizações. In: I Encontro de Ensino e Pesquisa em Administração e Contabilidade. EnEPQ 2007, Recife, 21 a 23 de novembro de 2007.

MENDONÇA NETO, O. R.; VIEIRA, A. M.; OYADOMARI, J. C. T. Notas Sobre o 'Rigor-Relevance Gap' no Contexto do Mestrado Profissional. Administração: Ensino e Pesquisa, v. 20, n. 1, p. 1-15, 2019.

MILES, M. B.; HUBERMAN, A. M. Qualitative data analysis: an expanded sourcebook. 2. ed. Thousand Oaks: Sage, 1994.

MITCHELL JR, J. V. Interrelationships and Predictive Efficacy for Indices of Intrinsic, Extrinsic, and Self-Assessed Motivation for Learning. Journal of Research and Development in Education, v. 25, n. 3, p. 149-55, 1992. 
MORAN, C. M. et al. A profile approach to self-determination theory motivations at work. Journal of Vocational Behavior, v. 81, n. 3, p. 354-363, 2012.

OLIVEIRA, P. A. et al. Motivação sob a perspectiva da Teoria da Autodeterminação: um estudo da motivação de alunos do Curso de Ciências Contábeis da Universidade Estadual de Montes Claros. In: $7^{\circ}$ CONGRESSO USP DE INICIAÇÃO CIENTÍFICA EM CONTABILIDADE, 2010, São Paulo. Anais do $7^{\circ}$ Congresso USP de Iniciação Científica em Contabilidade. São Paulo: FEA-USP, 2010.

PROGRAMA DE PÓS GRADUAÇÃO EM ADMINISTRAÇÃO (PPGA). Regimento interno do programa de pós-graduação em administração. Aprovado em reuniões do Colegiado do PPGA nos dias 01, 02, 06 e 12 de fevereiro de 2007. Alterado em reuniões do Colegiado do PPGA no dia 22 de dezembro de 2008. Alterado em reunião do Colegiado do PPGA no dia 24 de novembro de 2009.

PROGRAMA DE PÓS GRADUAÇÃO EM ADMINISTRAÇÃO (PPGA). Regimento interno do curso de mestrado profissional em gestão pública. Texto aprovado pelo Colegiado do PPGA em reunião plenária realizada em 20 de abril de 2009.

RIBEIRO, G. M. Autodeterminação para aprender nas aulas de violão à distância online: uma perspectiva contemporânea da motivação. Tese (Doutorado em Música) - Universidade Federal do Rio Grande do Sul, Porto Alegre, 2013.

RUFINI, S. E.; BZUNECK, J. A.; OLIVEIRA, K. L. de. Estudo de validação de uma medida de avaliação da motivação para alunos do ensino fundamental. Revista Psico-USF, v. 16, n. 1, p. 1-9, Jan-Abr. 2011.

SCHUNK, D. H. Self-efficacy and academic motivation. Educational psychologist, v. 26, n. 3-4, p. 207-231, 1991.

SHEN, B. Outside-school physical activity participation and motivation in physical education. British Journal of Educational Psychology, v. 84, n. 1, p. 40-57, 2014.

SILVA, L. et al. Cuidar de famílias de idosos em final de vida na Estratégia Saúde da Família. Rev. Latino-Am. enfermagem, v. 21 n.1, Jan-Fev. 2013.

SIQUEIRA, L. G. G.; WECHSLER, S. M. Motivação para a aprendizagem escolar: possibilidade de medida. Avaliação Psicológica, v. 5, n. 1, p. 21-31, 2006.

SZILAGYI JR., A.; WALLACE JR., M. Organizational behavior and perfomance. 5. ed. USA: Harper Collins Publishers, 1990.

VELHO, L. Evasão na pós-brasileiro: uma crise em formação? Jornal da Unicamp, Campinas-SP, 27, jun-jul. 2005.

VERGARA, S. C. Projetos e relatórios de pesquisa em administração. 13 ed. São Paulo: Editora Atlas, 2011.

VIEIRA, M. M. F. Por uma boa pesquisa (qualitativa) em administração. In: VIEIRA, M. M. F.; ZOUAIN, D. M (Org.). Pesquisa qualitativa em administração. Rio de Janeiro: FGV, 2004.

WECHSLER, S. M. Estilos de Pensar e Criar: impacto nas áreas educacional e profissional. 2006. 
WELTERS, R.; MITCHELL, W.; MUYSKEN, J. Self determination theory and employed job search. Journal of Economic Psychology, v. 44, p. 34-44, 2014.

\section{Miler Franco D'anjour}

Instituto Federal de Educação Ciência e Tecnologia do Rio Grande do Norte

Doutor em Administração - PPGA/UFRN. Professor Efetivo do Instituto Federal de Educação Ciência e Tecnologia do Rio Grande do Norte, na área de Administração.

\section{Bruno Campelo Medeiros}

Instituto Federal de Educação Ciência e Tecnologia do Rio Grande do Norte

Doutor em Administração - PPGA/UFRN. Professor Efetivo do Instituto Federal de Educação Ciência e Tecnologia do Rio Grande do Norte, na área de Administração.

\section{Márcia Fernanda Silva Macedo Galvão}

Universidade Federal do Rio Grande do Norte/UFRN

Doutora em Administração PPGA/UFRN.

\section{Anne Emília Costa Carvalho}

Universidade Federal do Rio Grande do Norte/UFRN

Doutora em Administração PPGA/UFRN. Professora Efetiva da Universidade Federal do Rio Grande do Norte/UFRN.

Recebido em: 17-1-2018

Aprovado em: 23-10-2019

Avaliado pelo sistema double blind review.

Editor: Coordenação do PPGA/UMESP

Disponível em http://mjs.metodista.br/index.php/roc 